\title{
EFFECTS OF MOBILE PHONE RADIATION ON PAROTID GLAND: IMMUNOHISTOCHEMICAL STUDY
}

\author{
Maher Al-assaf', Charif Barakat' , Majid G.A. Abo Fakher², Adnan Almalki ${ }^{3}$, Mourad A. Abo Fakher ${ }^{4}$ \\ 'Department of Oral Histology and Pathology, Faculty of Dentistry, Damascus University, Syria \\ ${ }^{2}$ Department of Oral Medicine, Faculty of Dentistry, Damascus University, Syria \\ 3Department of Telecommunication, Higher Institute of Applied Science and Technology "HIAST", Syria \\ ${ }^{4}$ Faculty of Medicine, Damascus University, Syria
}

\begin{abstract}
INTRODUCTION: The use of mobile phones has become a common phenomenon, with 6.9 billion subscriptions worldwide. The International Agency for Research on Cancer (IARC) has classified the electromagnetic fields emitted from mobile phone devices as group 2 b, i.e. "maybe being carcinogenic to humans".

ОвјестіVEs: The aim of present study was to investigate the potential effects of microwave radiation on the proliferation activity of parotid gland by measuring Ki-67 protein levels.

MATERIAL AND METHods: Sixteen male adult New Zealand white rabbits were divided fifty-fifty into control and experimental groups. The experimental group was exposed to the radiation one hour daily, six days every week for 6 months. The rabbits were sacrificed according to ethical methods and parotid glands were removed after the exposure period has ended; so, sixteen biopsies stained with monoclonal antibody Ki- 67 were obtained. The method of calculating the percentage of immunopositive cells from the total cells of fields was studied by light microscope at high magnification $\times 400$.

RESULTS: At 95\% confidence level, there were statistically significant differences in the mean positive ratio of Ki-67 protein between the exposed and unexposed group of rabbits to microwave-radiation.

Conclusions: The increase in immunoexpression to Ki-67 in the experimental group can be explained by an increase in proliferation within the parotid glands in response to harm caused by mobile phone radiation.
\end{abstract}

KEY WORDS: Ki-67 antigen, parotid gland, microwave-radiation, mobile phone, electromagnetic field.

J Stoma 2020; 73, 3: 112-117

DOI: https://doi.org/10.5114/jos.2020.96811

\section{INTRODUCTION}

Nowadays, non-ionizing radiation is widely spread; its most important source is the microwave-radiation produced by mobile phone devices, which in recent years have been used by most of the world's population [1].

For many years, an intense dispute has been carried out about the seriousness of mobile phone radiation, and researchers have not come yet to a final conclusion about the adverse role of this radiation entering the human body, but what is agreed, is the presence of this radiation in various health issues [2].

The International Agency for Research on Cancer (IARC) has classified electromagnetic fields caused by mobile phones as group $2 \mathrm{~b}$, i.e., they may be carcinogenic to humans $[3,4]$.

\section{JOURNAL OF} STOMATOLOGY CZASOPISMO STOMATOLOGICZNE

AdDress For CORRESPONDENCE: Dr. Maher Al-assaf, Department of Oral Histology and Pathology, Faculty of Dentistry, Damascus University, Syria, e-mail: e-mail: dr.maher.assaf1990@gmail.com 
Studies are under way to assess long-term health effects of mobile phone use. Regarding the large number of mobile phone users, it is important to perform all necessary studies on these phones to understand and monitor their potential public health impacts [5].

Since 2000, several studies have been conducted on mobile phones influence on public health, especially carcinogenic effects on the brain, salivary glands, and other neoplasms in the head and neck region [6].

Microwave radiation has a frequency ranging 0.3$300 \mathrm{GHz}$ and is located between radiology and infrared fields [7].

Micro-wave radiation is not ionized and have high tissue temperature effects, and in view of the frequencies used by mobile phones, most of the energy is absorbed by the skin and other surface tissues, which results in very little rise in temperature of the brain and other parts of the body [8].

Many studies on the non-thermal effects of microwave-radiation on the biological system have been conducted during the past thirty years, and some of these studies indicated:

- an increase in oxidation intensity [9],

- an increase in the permeability of the erythrocyte membrane and an increase in its dissolution [10],

- an effect on the cerebral vasoconstriction with an increase in the flow of calcium carbonate [11],

- an influence of the monocyte-dependent immunoregulatory mechanisms responsible for the initiation of immune response [12].

Since the parotid gland is placed directly under the skin of the face, it is one of the most exposed organs to the effect of radiation emitted from a mobile phone $[4,13]$. Therefore, there are studies assessing a relationship between an exposure to microwave-radiation and neoplasms of the parotid gland, and several studies indicated no association of parotid gland neoplasms with an exposure to mobile phone radiation [14]. However, these studies are still inadequate because of limited exposure period [15].

$\mathrm{Ki}-67$ is a human nuclear protein expression, which is associated with cell proliferation used as a proliferation marker to measure the division of cells in human neoplasms [16]. It is a nuclear protein expressed during the interstitial phase (G1-S-G2) within the nucleus, while in the division phase (M) is expressed on the surfaces of chromosomes. There is no expression during the phase g0 because this protein is destroyed rapidly when the cell enters the non-proliferation state $[17,18]$.

\section{OBJECTIVES}

This current study aims to investigate the potential effects of microwave-radiation on the proliferation activity of glandular cells in the parotid gland by studying Ki67 protein levels.

\section{MATERIAL AND METHODS}

\section{ANIMALS}

An approval was gained from the ethics committee of the Damascus University to conduct this study (approval No: 2033/2016).

The sample consisted of sixteen parotid glands removed from sixteen adult male New Zealand white rabbits that were divided evenly into two groups: experimental group (g1) rabbits exposed to microwaveradiation and control group (g2) rabbits not exposed to microwave-radiation.

\section{EXPERIMENTAL PROCEDURES}

A third generation (3G) device Samsung Galaxy J1 Mini Prime (model SM-J106H/DS) was used. This 3G mobile phone supports four Universal Mobile Telecommunications System (UMTS) bands (B1, B2, B5, and B8 with 2100, 1900, 850, and $900 \mathrm{MHz}$, respectively). In the present study, it has been confirmed which band is active in the country of this study depending on the "country-based mobile phone network frequency bands coverage guide", which indicates that these devices run on $\mathrm{B} 1$ mode $(2100 \mathrm{MHz})$. Also, the same was confirmed after contacting the telecommunications company (Syriatel Mobile Telecom S.A.).

The $3 \mathrm{G}$ mobile phone devices emit much more electromagnetic radiation, since they run on a higher frequency compared to second generation phones [19].

During experimental time, the rabbits exposed to microwaves were kept in glass cages [20] equipped with ventilation openings specially designed for this research, according to a uniform size $(30 \mathrm{~cm}$ in length, $12 \mathrm{~cm}$ in width, and $18 \mathrm{~cm}$ in height). The rabbits were an average size, which did not allow a rotational movement, but a minimal lateral movement of the head and forward or backward movement of the rabbit's body [21].

The distance between the mobile device and the side face of the rabbit was $5 \mathrm{~cm}$ [22], and the distance between the two devices was $35 \mathrm{~cm}$ (Figure 1). Mobile phones were without vibration with a silent mode to reduce the stress of the animals. The head specific absorption rate (SAR) was $0.873 \mathrm{~W} / \mathrm{kg}$ as mentioned by the manufacturer and in the "specific absorption rate certification information" (quick start guide), which is included with the device when purchased. The power of radiation was $4 \mathrm{~W}$ (Watt), and the daily total dose of radiation was 14,400 J (Joule).

A virtual phone call was made between the two devices, i.e. sender and receiver. At the beginning of the call, animals were placed in the glass cages and daily calls were simulated [19].

The rabbits in the experimental group were exposed to mobile phone devices (call mode) for one continuous hour daily, 6 days per week, for 6 months. The rabbits 


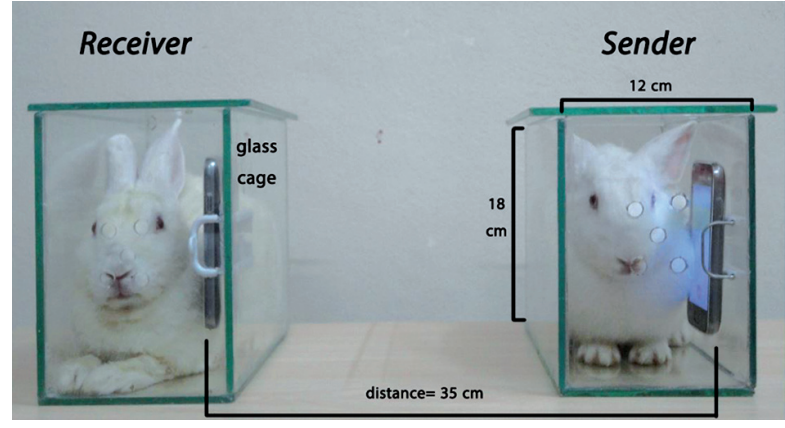

FIGURE 1. Exposure conditions and the position of rabbits (experimental group) in glass cages during the mobile phone radiations exposure

in the control group were exposed to mobile phone devices (switched off mode, no microwave radiation) for the same period.

After the end of the exposure period, rabbits were sacrificed according to ethical methods, and the parotid glands were removed unilaterally from each rabbit's side, which was exposed to the aforementioned mobile phone devices.

As for animals in the control group, they were subjected to the same conditions, considering that mobile devices were switched off. Therefore, 16 parotid glands isolated from 16 rabbits on the same side were obtained.

\section{IMMUNOHISTOCHEMICAL STAINING}

Immunohistochemical (IHC) detection of Ki-67 was carried out by using DAKO-LSAB-2HRP detection system. For IHC staining, the sections were cut at $4 \mu \mathrm{m}$ thickness using manual microtome. For IHC, sections were placed on pre-coated slides and incubated for 1 hour at $60^{\circ} \mathrm{C}$ in an incubator. For antigen retrieval, the sections were placed in a $1 \mathrm{mM}$ citrate buffer $(\mathrm{pH} \mathrm{6})$, and microwave was used with cycles of high, medium high, low, and very low, each lasting for 5 minutes and then cooled down

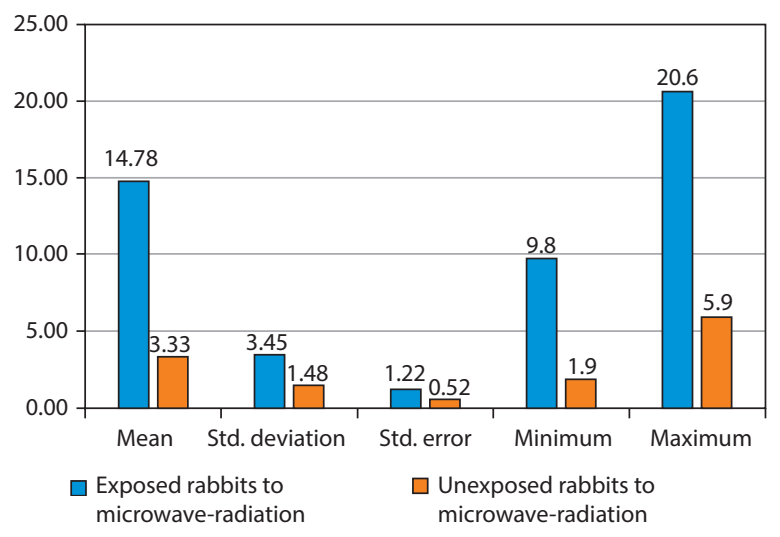

FIGURE 2. Arithmetic mean, standard deviation, standard error, minimum and maximum number of positive cells in the research sample, according to the exposure to microwave-radiation to room temperature. The endogenous peroxidase activity was blocked with $3 \%$ hydrogen peroxide for $10 \mathrm{~min}$ utes, followed by washing in $0.05 \mathrm{mM}$ Tris-buffered saline (TBS) at $\mathrm{pH}$ 7.4. The sections were incubated with precisely diluted mouse monoclonal antibodies against Ki67 (MIB-1 Dako, Japan) as primary antibodies for 1 hour at $37^{\circ} \mathrm{C}$. After washing in TBS, the sections were incubated with a secondary antibody conjugated with peroxidaselabelled dextran polymers (Envision + Dual Link/HRP System, Dako) for 30 minutes at room temperature. After rinsing with TBS, they were treated with $0.5 \mathrm{mg} / \mathrm{ml}^{3}$, 3 '-diaminobenzidine solution containing $0.001 \%$ hydrogen peroxide to visualize reaction products, and counterstained with hematoxylin for 3 minutes.

For positive control, sections of the colon for Ki-67 were taken.

\section{PROTOCOL OF HISTOPATHOLOGICAL STUDY}

The staining score of Ki-67 was evaluated under light microscope (OLYMPUS CX21) in glandular regions of the parotid gland as the percentage of glandular cells that exhibited a positive nuclear immunoreactivity to Ki-67 out of the total number of glandular cells in the field.

The percentage of positive cells was determined by counting four non-overlapping microscopic fields (four random fields) at $\times 400$ magnification according to the following equation:

Percentage of positive stained cells $=$ number of positive cells $\div$ number of total cells $\times 100$.

Every brown-staining glandular cell was considered positive, and no counts were performed in areas of necrosis or inflammation.

\section{STATISTICAL ANALYSIS}

SPSS software (v.20; IBM, Armonk, New York) was used to analyze the data obtained statistically, MS Excel 2019 program to perform the graphs, and $\mathrm{G}^{\star}$ power to calculate the sample size. The normality distribution was checked using the Kolmogorov-Smirnov test. T-test was used for independent samples to study significance of the difference in mean cell positive ratio between the exposed and unexposed group of rabbits to microwave-radiation.

\section{RESULTS}

Descriptive statistics are shown in the Figure 2. The expression of Ki-67 in the parotid glands of both the control and the experimental sample was investigated. Different expressions were observed in glandular cells. However, all samples were positive in both groups as in the forms (Figure 3).

To study the differences in Ki-67 expression between the control and the experimental group, the $t$-test of independent samples was applied. 

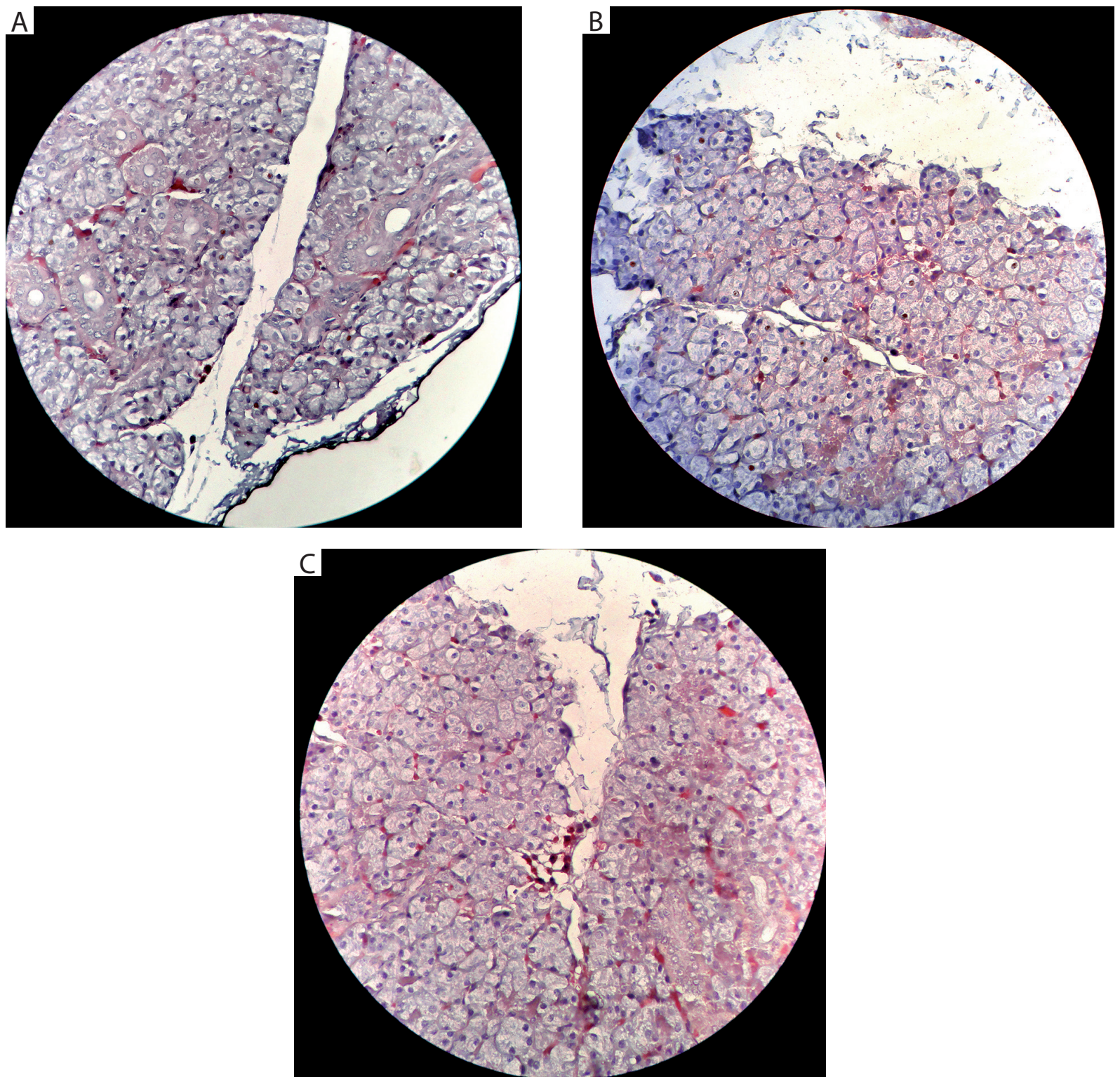

FIGURE 3. Histopathological photomicrograph (A, B, C) shows the nuclear immunoexpression of Ki-67 under $\times 400$ magnification (experimental group)

Table 1 shows that the value of the significance level was considerably less than the value of 0.05 , regardless of the studied stain; at 95\% confidence level, there were statistically significant differences in the mean positive ratio of the Ki- 67 protein between the exposed and unexposed group of rabbits to microwave-radiation.

\section{DISCUSSION}

Most experimental studies on salivary glands focused on traditional hematoxylin and eosin. In the study by Aydogan et al. [23], the authors concluded that the exposure to the microwave-radiation from a mobile phone

TABLE 1. Results of the $t$-test for independent samples to study the significance of differences in the mean positive protein ratio between the exposed and unexposed groups of rabbits to microwave-radiation in the research sample, according to the studied stain

\begin{tabular}{|c|c|c|c|c|c|c|}
\hline \multicolumn{7}{|c|}{ The measured variable = the proportion of positive cells } \\
\hline & Sig. (2-tailed) & Standard error difference & Mean difference & DF & $t$-value & Stained by \\
\hline $\begin{array}{l}\text { Significant } \\
\text { differences }\end{array}$ & 0.000 & 1.326 & 11.453 & 14 & 8.638 & Ki-67 \\
\hline
\end{tabular}


of third generation, with the frequency of 2,100 MHz, results in changes in the histopathological structure of parotid gland in rats, and these changes were represented in the epithelial cells, connective tissue, interstitial spaces, vascular system, size of nuclei, and gaps in cytoplasm [23]. Previous studies investigated the non-thermal effects of microwave-radiation supported the hypothesis of increased oxidative stress in the tissue exposed to this radiation. Akdag et al. [24] supposed that the exposure to such a radiation leads to an escalated level of free radicals, and since they are chemically unstable compounds, they seek stabilization by pilfering electrons from a stable molecule. The molecule itself becomes a free radical, and therefore strikes another stable molecule, which causes an imbalance between free radicals and antioxidants and eventually harming cells [25-27].

Consequently, these studies have used different types of antioxidants. Anan et al. [28], who used vitamin E in his research concluded that an exposure to microwaveradiation leads to regressive changes similar to changes reported in Aydogan et al. study [23]; however, these changes decreased when rats were injected with vitamin $\mathrm{E}$.

In another context, chemical studies have examined the flow rate of saliva. Goldwein and Aframian [29] concluded that the exposure to microwave-radiation increased salivary flow rate, but this increase was low in protein secretion due to continuous and cumulative damage to the glands.

During a literature review, we found only one immunohistochemical study by Helal and Abdelrahman [30], who used Ki-67 in exposed 25 male guinea pigs to $900 \mathrm{MHz}$ microwave-radiation. This exposure was of two types, acute and chronic. The acute exposure was for two hours a day for 3 months, while the chronic exposure was two hours a week for the same period.

At the end of exposure period, they collected the parotid and submandibular glands from the same exposed side, studied the expression of Ki-67, and concluded that there was a gradual increase in Ki-67 expression associated with increased exposure time. Moreover, the exposure to microwave-radiation produced proliferative effects in the glandular tissue.

The results of our study were convergent with the Helal and Abdelrahman [30] in terms of statistically significant differences, although the size of sample and the period of exposure varied.

The results of current study indicate an important increase in immunoexpression of Ki67 protein in the glandular tissue cells. This suggests an important increase in the ability of these cells for mitosis and division in response to the damage that is interpreted based on the theory of oxidative stress.

\section{CONCLUSIONS}

Within the limits of this study, we conclude that exposure to microwave-radiation from a third-generation mobile phones lead to an increased proliferation activity in the parotid gland in response to damage to the tissue structure.

\section{ACKNOWLEDGEMENT}

We want to point out that the laboratory tests were done at the research laboratory in the Department of Oral Pathology, Faculty of Dentistry at the Damascus University.

\section{CONFLICT OF INTEREST}

The authors declare no potential conflicts of interest with respect to the research, authorship, and/or publication of this article.

\section{References}

1. Rosado MM, Nasta F, Prisco MG, Lovisolo GA, Marino C, Pioli C. Effects of GSM-modulated $900 \mathrm{MHz}$ radiofrequency electromagnetic fields on the hematopoietic potential of mouse bone marrow cells. Bioelectromagnetics 2014; 35: 559-567.

2. Ranjitha GE, Austin RD, Ramasamy S, Bharathi CS, Angeline D, Sambasivam S. Influence of handheld mobiles on parotid: a cohort study. J Indian Acad Oral Med Radiol 2018; 29: 254.

3. Hardell L. World Health Organization, radiofrequency radiation and health-a hard nut to crack. Int J Oncol 2017; 51: 405-413.

4. Siqueira EC, de Souza FTA, Ferreira E, et al. Cell phone use is associated with an inflammatory cytokine profile of parotid gland saliva. J Oral Pathol Med 2016; 45: 682-686.

5. Röösli M, Lagorio S, Schoemaker MJ, Schüz J, Feychting M. Brain and salivary gland tumors and mobile phone use: evaluating the evidence from various epidemiological study designs. Annu Rev Public Health 2019; 40: 221-238.

6. World Health Organization. The International EMF Project: health effects of static and time varying electric and magnetic fields: progress report 1998-1999. Geneva: World Health Organization; 1998.

7. Johansen C. Electromagnetic fields and health effects - epidemiologic studies of cancer, diseases of the central nervous system and arrhythmiarelated heart disease. Scand J Work Environ Health 2004; 30: 1-80.

8. Mishra SK, Chowdhary R, Kumari S, Rao SB. Effect of cell phone radiations on orofacial structures: A Systematic review. J Clin Diagn Res 2017; 11: ZE01-ZE05.

9. Kahya MC, Nazıroğlu M, Çiğ B. Selenium reduces mobile phone (900 $\mathrm{MHz}$ )-induced oxidative stress, mitochondrial function, and apoptosis in breast cancer cells. Biol Trace Elem Res 2014; 160: 285-293.

10. Savopol T, Moraru R, Dinu A, Kovács E, Sajin G. Membrane damage of human red blood cells induced by low-power microwave irradiation. Electro- and Magnetobiology 1995; 14: 99-105.

11. Zhang J, Sumich A, Wang GY. Acute effects of radiofrequency electromagnetic field emitted by mobile phone on brain function. Bioelectromagnetics 2017; 38: 329-338.

12. Dabrowski M, Stankiewicz W, Kubacki R, Sobiczewska E, Szmigielski S. Immunotropic effects in cultured human blood mononuclear cells pre-exposed to low-level $1300 \mathrm{MHz}$ pulse-modulated microwave field. Electromagnetic Biol Med 2003; 22: 1-13.

13. Hashemipour M, Yarbakht M, Gholamhosseinian A, Famori H. Effect of mobile phone use on salivary concentrations of protein, amylase, lipase, immunoglobulin A, lysozyme, lactoferrin, peroxidase and C-reactive protein of the parotid gland. J Laryngol Otol 2014; $128: 454-462$. 
14. Johansen C, Boice Jr JD, McLaughlin JK, Olsen JH. Cellular telephones and cancer - a nationwide cohort study in Denmark. J Natl Cancer Inst 2001; 93: 203-207.

15. Liu YX, Li GQ, Fu XP, et al. Exposure to 3G mobile phone signals does not affect the biological features of brain tumor cells. BMC Public Health 2015; 15: 764.

16. Lopes VKM, Jesus AS, Souza LL, et al. Ki-67 protein predicts survival in oral squamous carcinoma cells: an immunohistochemical study. Braz Oral Res 2017; 31: e66.

17. Gerdes J, Lemke H, Baisch H, Wacker HH, Schwab U, Stein H. Cell cycle analysis of a cell proliferation-associated human nuclear antigen defined by the monoclonal antibody Ki-67. J Immunol 1984; 133: 1710-1715.

18. Takagi M, Ono T, Natsume T, et al. Ki-67 and condensins support the integrity of mitotic chromosomes through distinct mechanisms. J Cell Sci 2018; 131: jcs212092.

19. Dogan M, Turtay M, Oguzturk H, et al. Effects of electromagnetic radiation produced by $3 \mathrm{G}$ mobile phones on rat brains: magnetic resonance spectroscopy, biochemical, and histopathological evaluation. Hum Exp Toxicol 2012; 31: 557-564.

20. Aydoğan F, Aydın E, Koca G, et al. The effects of 2100-MHz radiofrequency radiation on nasal mucosa and mucociliary clearance in rats. Int Forum Allergy Rhinol 2015; 5: 626-632.

21. Kesari KK, Kumar S, Behari J. 900-MHz microwave radiation promotes oxidation in rat brain. Electromagn Biol Med 2011; 30: 219-234.

22. Mortazavi S, Owji S, Shojaei-Fard M, et al. GSM $900 \mathrm{MHz}$ microwave radiation-induced alterations of insulin level and histopathological changes of liver and pancreas in rat. J Biomed Phys Eng 2016; 6: 235-242.

23. Aydogan F, Unlu İ, Aydin E, et al. The effect of $2100 \mathrm{MHz}$ radiofrequency radiation of a $3 \mathrm{G}$ mobile phone on the parotid gland of rats. Am J Otolaryngol 2015; 36: 39-46.

24. Akdag M, Dasdag S, Canturk F, Akdag MZ. Exposure to non-ionizing electromagnetic fields emitted from mobile phones induced DNA damage in human ear canal hair follicle cells. Electromagn Biol Med 2018; 37: 66-75.

25. Dasdag S, Akdag MZ. The link between radiofrequencies emitted from wireless technologies and oxidative stress. J Chem Neuroanat 2016; 75: 85-93.

26. Kivrak EG, Yurt KK, Kaplan AA, Alkan I, Altun G. Effects of electromagnetic fields exposure on the antioxidant defense system. J Microsc Ultrastruct 2017; 5: 167-176.

27. Di Ciaula A. Towards 5G communication systems: are there health implications? Int J Hyg Environ Health 2018; 221: 367-375.

28. Anan H, Gawish M, Amer M, Ibrahim N. Effects of low magnetic irradiation on morphology and ultrastructure of parotid glands in rats and amelioration by vitamin E. J Cytol Histol 2012; 3: 139-142.

29. Goldwein O, Aframian D. The influence of handheld mobile phones on human parotid gland secretion. Oral Dis 2010; 16: 146-150.

30. Helal M, Abdelrahman M. Ki-67 expression on major salivary gland exposed to mobile cell phoneradiation. Egyptian Dental Journal 2012; 58. 